\title{
The Electronic Monitoring of Care Work-The Redefinition of Paid Working Time
}

\section{Sian Moore and L.J.B. Hayes}

This chapter explores the electronic monitoring (EM) of homecare work in the UK in terms of its impact upon care workers and the employment relationship. It considers the rationale for the use of EM and how far EM is designed to protect workers (Ball 2010) and service users, but may, in the context of the local authority commissioning process, involve not only the surveillance of workers but also the reconfiguration of paid and unpaid working time. This reconfiguration can redefine homecare workers' labour in both quantitative and qualitative terms. Commissioning on the basis of 'client contact only payments' (where providers are paid only for the time that care workers are in the service-user's home) excises so-called 'unproductive' labour and undermines worker autonomy and discretion, but also the relational aspects of care.

S. Moore (\&)

University of Greenwich, London, UK e-mail:

s.moore@greenwich.ac.uk

L.J.B. Hayes

Cardiff University, Cardiff, UK

(c) The Author(s) 2018

P.V. Moore et al. (eds.), Humans and Machines at Work,

Dynamics of Virtual Work, https://doi.org/10.1007/978-3-319-58232-0_5

101

\section{s.moore@greenwich.ac.uk}

102 S. Moore and L.J.B. Hayes

Homecare workers provide personal care to older and disabled people in their own homes. The scaling back of state-funded support and the marketisation or refamiliarisation of welfare provision has involved shifting the workforce from the public to the private sector (Dominelli and Hoogvelt 1996; Ungerson and Yeandle 2007). Whilst once delivered directly by local authorities, homecare is now overwhelmingly commissioned and, at the time of writing, was deemed to be in crisis with public spending on adult social care set to fall to less than $1 \%$ of GDP (Kings Fund 2016; UKHCA 2015). ${ }^{1}$ Budgetary pressures on the commission- ing of care have produced measures designed to increase productivity through reduced costs and intensified labour. The homecare sector is highly gender segregated and characterised by the employment of workers on zero-hours contracts (ZHCs); in 2016 it was calculated that $58 \%$ of homecare workers were on ZHCs (Skills For Care 2016). Under ZHCs there is no obligation 
upon the employer to provide work or on the worker to accept work, accordingly both working time and pay are unpredictable (Adams and Deakin 2014). ZHCs reflect employer pref- erences for work-on-demand scheduling (Jacobs and Padavic 2015) which they argue is justified by the significant weekly fluctuations in demand for care. Homecare is further marked by the non-payment (or inadequate recognition of) travel time between care visits (estimated by the UK Homecare Association at 19\% of homecare workers' time) and by episodic or intermittent working (Supiot 2001) in the form of unpaid gaps or 'waiting time' between visits and indeed ZHCs facilitate this unpaid labour.

It is important to note the gendered history of homecare which provides the context for what might be seen as the restoration of women's unpaid care work. Homecare was only established as formal employment from the 1970s, with regular fixed hours, written contracts, employment security, access to an occupational pension and latterly to equal pay, along with paid training and supervision (Dexter and Harbart 1983). Since the demand for homecare peaks at certain times during the day (mornings, lunchtimes, evenings and bedtimes) so-called 'down time'- when demand is reduced-has been seen as problematic and as an unnecessary 'cost' for homecare services. It is this so-called paid 'downtime' between homecare visits that has been removed in the

\section{s.moore@greenwich.ac.uk}

\section{The Electronic Monitoring of Care Work—The Redefinition ... 103}

transfer of homecare workers from direct employment by the local authority to the private sector. ZHCs have provided the contractual basis for the removal of 'down time' and accommodated fluctuations in local authority demand for homecare.

Private providers are increasingly required by local authorities to use EM systems to track the real-time location of homecare workers. Time sheets are replaced by integrated computer-telephone technology to record service user visits. Logging in and out may be done through serviceusers' telephones (as in the case studies discussed here), but homecare workers may also swipe tags on clients' files with smartphones or use mobile telephones with GPS technology. The system matches the care worker's unique number to the database of service users at the EM supplier's call processing centre, logging the time the call was made and aligning this to the roster/schedule of care-the care worker repeats the procedure when leaving.

EM has been marketed as a protection for service users and workers but as Rosenbat et al. write 'the line between workplace surveillance as coercive and protective/performance-enhancing is in constant tension in labor relations, especially as work shifts beyond a specific, bounded location and spills over into a multiplicity of spaces and sites that are neither entirely private nor explicitly the purview of employers' (2014:14). 
Whilst Himmelweit (2005) suggested that there have been difficulties in increasing productivity in care, EM introduces a new level of managerial control into an occupation where previously, because of its location, managers had only limited remit and attendance was certified by the service-user (Dexter and Harbart 1983). In fact, EM may substitute for the costs of supervision and management, which are not fully funded by local authority contracts. Many homecare workers rarely see a super- visor or manager or colleague and receive their rotas via mobile telephone. EM in homecare has the potential, as Levy proposes for drivers in logistics, to abstract labour from its local and biophysical contexts operationalising job performance as a set of metrics governable by remote parties. The context of work is redefined to legitimate certain types of experience and knowledge and to create new meanings and social orders (2015). In its reduction of the 'care package' (a description suggesting a commodity

\section{s.moore@greenwich.ac.uk}

\section{S. Moore and L.J.B. Hayes}

rather than a relationship) to a series of tasks and number of minutes, EM may threaten the relational aspects of homecare and undermine the discretionary effort that sustains it. The legacy of gendered domestic labour has underpinned the notion of discretionary labour in care work. For Glucksmann and Lyon 'care is significant as an activity that is simultaneously work and non-work' (2006). These arguments have been used to explain reliance on discretionary effort in care work suggesting that care does not fit well within established labour process mechanisms as a commodity for exchange (Bolton and Wibberley 2014). Rubery et al. argue that current HR practice relies upon care worker 'goodwill' since the structure of the homecare market hampers the potential for effective HR strategy to alleviate inadequate wages and high levels of staff turnover at the level of the individual firm (2015).

Brown and Korcynski's research on the impact of EM in public sector homecare services found that whilst labour was intensified it did not reduce discretionary effort (2010). However, their workplace survey involved homecare workers directly employed by the local authority, EM had not so far affected their working time or income, suggesting the importance of the wider context in considering how technology shapes the labour process, including social relationships (Prichard et al. 2014; Ball 2010). However, Rubery et al.'s 3-year study of the recruitment and retention of the wider social care workforce in the public and private sector (commissioned by the Department of Health between 2007 and 2010), anticipated that EM in homecare could reduce pay by 'restricting paid work time, to time actually spent in people's houses' (2011) - this chapter takes this proposition as its starting point.

The chapter is based upon case studies of homecare commissioning, encompassing the perspectives of EM suppliers, local authority com- 
missioners, care providers and the experience of care workers. It captures variation in the use of EM between local authorities committed to ethical homecare and those authorities paying for care on the basis of contact time only or minute-by-minute commissioning. Such variation reflects the tension between the rhetoric of worker safety and workplace surveillance as coercive (Roseblat et al. 2014). The case studies show that whilst the narrative underpinning the use of EM is its facility to ensure compliance and to safeguard service-users and care workers, it is also

s.moore@greenwich.ac.uk

The Electronic Monitoring of Care Work-The Redefinition ... 105

being used to instigate local authority savings by delineating paid and unpaid working time, with ZHCs providing the contractual basis for the removal of so-called 'unproductive' work from the remit of paid labour. The chapter privileges the voices of care workers who perceive EM as an attack on their autonomy and discretion and as involving the degradation of their work.

\section{Research Methods}

The study draws upon a number of case studies of the local authority commissioning of homecare. Primarily, it is based upon case studies of two neighbouring local authorities (Authority A and Authority B) in the South West of England between 2014 and 2015 and particularly, the recommissioning of homecare in one of them. This research was funded by a British Academy/Leverhulme small grant and sought to explore the impact of electronic monitoring on wages, hours and the employment experiences of homecare workers. These case studies were selected because of the proximity (at the time) of the researchers and access to key local actors. This study is supplemented by more recent research in 2016 on the implementation of UNISON's Ethical Care Charter based upon nine case studies, including seven local authorities that had adopted the Charter. These case studies considered whether and how EM was used in the provision of homecare, but particularly, in authorities that were committed to improving pay and conditions for care workers.

The case study method facilitated a combination of data collection methods from a variety of sources (Dooley 2002). The role of EM in the commissioning process was captured by textual analysis of supporting documentation in the form of commissioning strategies, consultations, tender documents, along with sales and publicity material for a large supplier of EM systems. The perspective of the technology supplier and technology design is advocated by Collin-Jacques and Smith (2005) and illuminates possible rationales for the adoption of EM. The South West case studies involved interviews with two representatives of the supplier 
of electronic monitoring software and systems; seven in-depth interviews with six local authority officers involved in the commissioning of

s.moore@greenwich.ac.uk

\section{S. Moore and L.J.B. Hayes}

homecare services and service management; five interviews with senior managers or owners of three homecare providers; plus 14 in-depth interviews with female homecare workers working for different homecare providers and with experiences of EM in the area covered by the local authorities. Since the recommissioning process in one authority was prolonged and encountered difficulties, the research took on a longitudinal perspective with reinterviews with commissioners and providers to capture the tendering process and its outcomes. The UNISON case studies were similarly based upon interviews with 18 local authority commissioning or service managers, nine providers, 11 care workers and 13 UNISON representatives. All interviews were face-to-face, based upon informed consent and recorded and transcribed. The authorities are anonymised to ensure that respondents cannot be identified.

Whilst case studies are not representative, the comparison of local authorities subject to the same national budgetary pressures is instructive in capturing the scope for variation in the adoption and application of tendering requirements including EM. Triangulation was achieved through analysis of EM in the homecare strategies of a range of local authorities found on the web which confirmed the use and rationale for EM. Microlevel textual analysis pinpoints the discursive construction of EM in marketing and publicity material as well as in council documen- tation, which articulates a purported rationale for the implementation of EM systems. Critical discourse analysis of both interview and documentary texts (Roper et al. 2010) captured dissonance between theory and practice, particularly, in the discussion of budgetary issues. Social and political contextualisation was brought by macro-analysis of the wider socio-political practices evoking the political economy of care. This context was informed by previous research on the way ZHCs reconfigured paid working time and a desire to understand how the introduction of EM would affect this trend (Bessa et al. 2013; Low Pay Commission 2013). The reporting of extensive interviews with care workers and the local authority officers and providers that mediate its use is designed to privilege subjectivity and supports the widespread use of the actors' own words below. This is important since, as Zuriek puts it, the subject of surveillance on exposure to the observing gaze is dissolved and 'reconstituted in the abstract' through performance metrics (Zureik 2003: 39). 


\section{Electronic Monitoring in Care}

EM is used to track missed, late and over-running visits, but also where scheduled visits are cut short. The real-time data is visible to the homecare worker's employer and, where local authorities require provi- ders to use a particular EM system, to local authority officers. Here, the authority owns the intellectual property rights to all information on the Electronic Monitoring System, including care worker data. Ironically whilst local authorities no longer directly employ homecare workers, a computer screen in a council office can identify each worker and their location and calculate the costs of the service as they are delivering it. Whilst EM allows for the analysis of care visit data, it additionally generates invoices directly for payment processing. Related systems provide an integrated scheduling, monitoring and financial management solution which, in the case of one supplier, promises to 'take worker productivity to a new level' improving the management of work. Electronic Scheduling allows providers to allocate the most appropriate care worker for each care plan or visit based upon a range of factors including availability, location and skill set.

Authority A had required Framework providers to adopt EM since 2008. Authority B had previously only expected larger providers to do so, but it was now a requirement under the recommissioning process. Commissioning documentation and interviews with local authority representatives drew, often simultaneously, upon three narratives legitimising the use of EM: worker and provider compliance; safeguarding for both service users and care workers, and cost savings. Local Authority A required external providers to use its specified EM system and stated that it had introduced it for a range of reasons including to promote safety for lone workers and service users, to improve the quality and visibility of the service, to reduce administration costs and to ensure invoices from providers were linked to actual hours of care commissioned and delivered.

In terms of safeguarding local authorities and suppliers emphasised that EM can protect workers from service-users' complaints that they had not turned up or were late or left early, as a Commissioning Officer in Authority A stated:

\section{s.moore@greenwich.ac.uk}

\section{S. Moore and L.J.B. Hayes}

The other thing that EM has done for us is it's been very useful with safeguarding and it's been useful for complaints. So if we have complaints where people say the care worker's not turning up and the providers say actually they are, we're able to check that. And we're able to check visit times where safeguarding is an issue. For example, we've had instances 
whereby there's been an issue of neglect, perhaps somebody has not been given medication, perhaps quite serious medication that they need. So we're able to check on EM whether staff were there and clearly what we're not able not to do with EM is to check that people have had their medication, but we can at least check that people are there.

For Rosenblat et al. the rhetoric of safety may be one justification for surveillance technologies, 'although safekeeping is seldom their sole purpose or effect' (2014: 3). Publicity material for the leading supplier of EM technology states it is designed to improve efficiency and quality assurance in homecare. Whilst safeguarding service users and staff, the supplier also promises financial benefits and EM has been promoted on the basis of significant savings. For local authorities the system offers a threeway analysis of commissioned (purchased) time, versus planned (scheduled) time, versus actual or delivered time so that providers may be paid only for 'contact time' with service users. As a marketing manager explained this means authorities no longer pay for the time between actual and scheduled visits, discouraging shortened visits that might be the result of call-cramming (back-to-back visits):

What's commissioned compared with what's planned, compared with what's actually delivered, is totally different. The difference between commissioned and planned quite often is somewhere between 10 and 20 per cent. So quite often the planned package once it goes out to an external provider will be somewhere between 10 and 20 per cent different from what was commissioned largely based on the ability of the care provider to actually deliver for that service user based on all the other business that they have to manage. And that's understood within the market to be a key dynamic. However, then what's actually delivered will depend on how effective the provider is at actually planning the time of their care workers and all the issues in the market, things like not allowing for travel time, call-cramming as a result of that. With the best will in the world,

\section{s.moore@greenwich.ac.uk}

The Electronic Monitoring of Care Work-The Redefinition ... 109

and allowing as much time as you possibly could to run a commercial business and still make a reasonable profit, visits do start to run late once you get to the back end of the day. And as a result of that, the half an hour visit often becomes an 18 minute visit or a 20 minute visit. The difference between commissioned and actual delivery can be anything up to 40 per cent difference. And that's really why a lot of councils, and we came back to drivers, for many councils it was about making sure that they were only paying for the care that was delivered once they'd outsourced the bulk of their home care to the external provision.

The EM supplier in question reported working with 65 local authorities and publicity material confirmed direct cost savings between organisa- 
tions paying on commissioned time and those monitoring and paying on actual delivery of upwards of 37\%. The UK Home Care Association (UKHCA), which represents homecare providers, notes that with very few exceptions councils pay providers by reference to 'contact time' only, leaving the provider to meet the full costs of the service and placing severe pressures on the payment of all working time including travel and training and supervision costs. The UKHCA believes this is a universal practice to reduce the transactional costs of invoice processing for councils (2015: $15)$.

It was reported that in Local Authority A, since it had begun paying providers for only the care delivered, it had made $10 \%$ savings in its Adult Social Care purchasing budget. Its Framework Agreement obliges providers to transfer rostering information five days in advance to the council's system. Invoices are produced from the EM and are paid only if they are submitted via EM (in exceptions the provider is charged by the council for processing invoices). Payments are made where the total visit time is within the parameters defined by the council, where they are in excess of this time there is an investigation by council officers, but payment will not be authorised where they consider variation to be outside the agreed requirements and providers are instructed not to provide visits in excess of contractual arrangements without authorisation by the Council contracts team. The Council commissions in half hour bands as a minimum and then 15 minute blocks after that. A care worker reported on the implications of the banding system:

\title{
s.moore@greenwich.ac.uk
}

\section{S. Moore and L.J.B. Hayes}

\begin{abstract}
You'd be out on say like $£ 8$ an hour, and if you were in there quarter of an hour out of a half hour duty, then you'd only get quarter of an hour. If you were there 20 minutes, you wouldn't get 20 minutes pay, you'd still get your quarter of an hour. But if you stayed there 30 minutes, you'd obviously get your 30 minutes. They basically rounded it up or rounded it down to the nearest quarter of an hour or to the nearest half an hour. So in my eyes they were penny pinching. They were trying to save money. That's why I left because I felt I would end up rushing the job instead of actually caring about the work and in my eyes that's not caring. [Careworker6]
\end{abstract}

The commissioning officer for Local Authority B confirmed that, as in Local Authority A, the introduction of EM has yielded financial benefits for the Council:

We've had a cost saving since we've introduced Electronic Monitoring. What we were doing was we were paying providers on what we commissioned. So if we commissioned ' $x$ ' number of hours, they would then be paid for ' $x$ ' number of hours, what we now do is we pay providers on what we call actuals, so the actual time they've spent with the service user, 
because we were paying too much, because often what was provided wasn't what was commissioned - perhaps the service user's needs changed or whatever or often it can be the case that they would say to the provider: "I don't want you today because my daughter's here," or whatever. There's a legitimate reason for turning the provider away.

The quote demonstrates the contingent nature of homecare and here providers and ultimately workers absorb the risk represented by the fluctuations in the demand for care, which might (as in the quote) be down to changes in service users' plans, or be as a result of hospitalisation or death. In Local Authority A, if a service user is admitted to hospital on an emergency basis the provider may charge for the next planned visit within 24 hours if the provider was unaware of the admission-no further charges are made until the service resumes-recommencement of the service is required within 24 hours.

In Local Authority B, the requirement to adopt EM in its recommissioning process involved a move from a banding system,

s.moore@greenwich.ac.uk

The Electronic Monitoring of Care Work—The Redefinition ... 111

where workers would be paid (as in Authority A) to the nearest 15 minutes, to being paid to the minute, as a provider anticipated:

If they do minute-by-minute billing, and that person leaves early, they will only get paid their 20 minutes. Whereas at the moment if the girls stay over 23 minutes they are paid for a 30 minutes call; so it comes into sections of time about how much they get paid and if they stay 22 minutes they only get paid 15 minutes - there's a cut-off point.

Whilst EM can be used to ensure that visits are not cut short, in this case it was also designed to guard against care workers 'hanging around' to the cut-off point to make up their pay. The commissioning of care on 'actual' contact time suggests that any time not spent in the engagement of care tasks in the service-user's home is not productive and therefore does not have to be paid for. This includes training, management and supervision. It also includes provider overheads and another provider reflected upon the downward pressure on cost in the retendering exercise on top of the impact of minute-by-minute commissioning:

Well they're saving, if the carers are going in and it's a 30 minutes call and they go in for 20 minutes, they only get paid for the 20 minutes. So in a week if that happens, it all adds up doesn't it, and if you're doing a lot of calls it's going to add up somewhere along the line isn't it? You are going to have to be much tighter on your scheduling and make sure that you have allowed adequate time for everything, travel time, traffic, all even- tualities 
so that that person can be allowed the time that they've actually got for that person otherwise they are going to lose money. When you think what has got to come out of that hourly charge rate it's frightening - we put in the cost of the manager, the cost of the coordinator or two coordinators, the cost of senior carers, the cost of an office, the cost of the company HR all of that - then there's the IT, the EM system, the expenditure on that - that's all got to come out of the $£ 14.20$; the hourly pay rate - the lowest rate is $£ 7.45^{2}$, national insurance, pensions -you try and work out the maths because I can't!! The person from the bid team that was doing it came back to me and said: "Are you having a laugh?" And I said, "No, I'm not-that is the highest we can bid at." She said, "You just can't do it." The most frightening thing about the whole process

\section{s.moore@greenwich.ac.uk}

\section{S. Moore and L.J.B. Hayes}

is the charge rate. They've set it and the maximum they've set it at is $£ 14.20$, which is a cut for us. We're trying to pay our homecare workers a living wage, we're trying to pay appropriate mileage, travel time and on the margins that you've got on the charge rate that [the local authority] are setting you can't do all of that - it is impossible.

In fact, this provider lost out in the recommissioning process, reporting that one of the four successful providers had tendered at $£ 12.20$ an houra rate which the director of the company stated was 'unviable' and the exit of large providers from the publicly funded care market has been documented ADASS (2015). In the case studies of authorities that had adopted UNISON's ECC there was a general rejection of minute-byminute commissioning, which was perceived as incompatible with ethical care and in particular the payment of a Living Wage and travel time. Here, there was acceptance that to deliver the ECC charge rates had to reflect these costs and, where the Charter had been suc- cessfully implemented, authorities had provided extra investment. Only one of the seven authorities paid providers on contact time to the minute. Significantly, one of its providers reported that it absorbed the difference between contact and scheduled time in order to protect care workers' pay and suggested that providers often accommodated such costs to avoid the costs of staff turnover.

ZHCs effectively remove both waiting time between visits and travel time from the remit of paid labour, however, since the worker is available to the employer during those times the line between paid and unpaid labour may be blurred. EM represents a step change as it clearly delineates productive and apparently 'unproductive' labour time for the purposes of pay. One key aspect of this is that workers are penalised for running late, whether through call-cramming, the unexpected demands of service users or travel difficulties. For homecare workers employed by providers in Authorities A and B, EM was perceived to have resulted in cuts in pay, 
one said she had lost pay because call-cramming meant she would arrive late to visits and was sometimes earning only $£ 120$ a fortnight. Another care worker recalled that her co-worker had calculated that EM had meant a reduction in pay of $£ 50$ per week and she described how each visit introduced new sources of unpaid time that added up over the day.

s.moore@greenwich.ac.uk

The Electronic Monitoring of Care Work-The Redefinition ... 113

As other care workers reported, whilst EM meant they would not get paid for cutting calls short, they were also not paid where calls overran scheduled time because of unforeseen circumstances:

When I started with them there was no clocking in, but that did come into play. And if you moaned about not having enough travelling time, they would just take those clients off you and then you would have a big gap. So you would sit and wait for an hour and a half before your next one or an hour. And then they brought the clocking-in time as well, it was supposed to allow for travelling time. And on our call sheet it would have 'Client 1: Address' and then they would put a five minute gap. They said that you would have five minutes to get there. That actually happened for about two or three months and then the time sheets were coming back normal, just like before, with no travelling time and clients' time starting in the middle of the previous client's time. You were driving from A to B and just manic, dangerous driving because you're rushing to get there. And then the poor clients - because you're 15 minutes late, and it's not fair on themand then you've got to leave on time. So you're clocking in late because you've got no travelling time and you're clocking out on time but only getting paid then 15 minutes for a half an hour call. But you are actually still working and then, they said to us if we went over our time with a client we wouldn't get paid because that's not the contracted hours. The council won't pay them, so the agency won't pay us. So if we did an extra hour, which happened quite often if somebody has had a fall or somebody wasn't well, and you stay on because it's your duty of care, we wouldn't get paid that [Careworker8]

The extent of unpaid labour is underlined by another careworker:

The last shift I did from 7 till 2 I had six calls and I had $31 / 4$ hours so availability is 7 hours and I got paid $31 / 4$. But I had my uniform on obviously I couldn't do anything else. That was a fairly typical day, getting paid for about half the time I am available for work. If I had a full day, it would be from 7 in the morning till 10 at night and then you probably might get 6-7 hours' pay out of that. [Careworker12] 
For Ehrenreich (2001), time and tracking technologies can be used to constrain employee attempts to 'steal' time from employers and, in the case of homecare, this extends to providers. Local Authority B antici- pated that the requirement to utilise EM would cut 'illegitimate' manual entries based upon the commissioned time, since the council could monitor centrally on a real-time basis. Whilst there was some acceptance that failure to $\log$ in and out could be legitimate, there was also suspicion that both providers and care workers could manipulate the system as one commissioning officer commented:

The providers can override the system so, for example, some service users would not let the care worker use the phone for whatever reason. And then it has to be a manual entry back at the office. We just need to be very careful about making sure that those manual entries are legitimate. If the care worker logs in at a service user's house then it says how long they've been and how long they haven't been there. The ones that are done back at the office we don't know whether they're legitimate or not. We can do spot checks with those, what we do is we've analysed the providers so we check how many are doing the manual entries back at the office. And some providers will stick out like a sore thumb.

For care workers back-to-back visits ('call-cramming') and insufficient travel time between them drives them to cut visits short to ensure they get to the next service user ('clipping'); this is further encouraged where travel time is not paid in order to minimise the extent of unpaid labour and because of the direct relationship between contact time and pay. One provider described how care workers may attempt to claw back unpaid travel time or paid time lost through call-cramming by cutting visits short:

I think people forget to log-out, and in some cases genuinely. I think other cases they're trying to work the system. So you've got a 30 minutes call, you might have only stayed 20 minutes but you haven't logged out so you're at the next client's. Whereas if they'd have stayed their full 30 minutesyou can't be at Gladys's at twenty past seven when you only got to Bert's at 7 ,

\section{s.moore@greenwich.ac.uk}

The Electronic Monitoring of Care Work-The Redefinition ... 115

and it's a 30 minute call. So they're shortcutting the calls, so it can be worked - it can be abused, shall we say, not worked - and, obviously, we have to, as providers, clamp down on that and try and address those things. I think some of the girls will try and work it so that they're short- ening their calls but trying to get the full 30 minutes. And it's not helped when you've got people in that round that either won't let you use their telephone, because we've got some people who won't let you use their phone. Or they 
haven't got a phone so you can't always track it as closely as you would like to.

Care workers confirmed that service-users could be reluctant to let them use their phones, having to be reassured that they would not be charged, or that phones might be in use when they needed to clock in or out. Yet, in Authority B no payment is made where visits have not been logged correctly. Rather than workers stealing time, care workers reported losing pay when they forgot to or could not clock in, which was often a result of rushing from one call to another:

As Levy (2015) describes for fleet management systems used to track drivers, real-time monitoring removes the ability of workers to reconstruct their time, which may be to demonstrate or manufacture compliance. EM thus undermines informal worker power as well as their formal autonomy at work. As one care worker describes, it also removes discretion, forcing workers to stay in service users' homes where they judged that they were not needed:

If the house visit was for, say, half an hour, you had to log in when you got there, say 12.30, but you weren't allowed to log out; you had to stay there. If I went in for 30 minutes and they didn't want anything, they just wanted a cup of tea, a bit of toast and butter and I was only there 15 minutes, I would only have got paid for the 15 minutes. So I had to stay there right up until two minutes before I left so that I could get that pay. [Careworker2]

The removal of discretion was particularly felt in the context of the contingent and unpredictable nature of homecare work, in the context of

\section{s.moore@greenwich.ac.uk}

\section{S. Moore and L.J.B. Hayes}

variable travel and transport conditions and the vulnerability of serviceusers:

You could leave dead on time but they don't give you any time for travelling. You can be stuck in traffic 20 minutes, half an hour but you don't get paid for that. And then they're questioning you: "Why are you late?" And you've got traffic lights, you'll hit traffic, you could be stuck for ages. It's not a case of skiving off anywhere: you're stuck. Some people can spend half an hour on the loo or they could have had an accident where they mess themselves and you've got to stay there and clean them. You can't walk away. My argument is - which is what I've argued with them- you cannot walk away from a service user or a client whatever you want to call them, if they've had the accident where they've messed themselves or even if a client's had a fall. I went to a service user who had a fall and I rang an ambulance to get the person up and checked out. Then I rang in work because I was running really late. [Careworker9] 
As an officer responsible for quality assurance reported homecare workers perceived the surveillance of their work as indicating a lack of trust, once again drawing upon narratives of safety and service quality to support the implementation of EM:

I think at the beginning, some of the care workers found it a bit of a faff; felt it was a bit big brother-ish, which you can understand. Also you can understand some of them might have felt that it was there because of a lack of trust. But I think there's an understanding that if we are not able to monitor then how do we know this won't happen? In quality assurance, if it's not written down and somebody doesn't say what's happening, then it hasn't happened. It's better for the staff because of the fact that they can prove they've been there. They can prove they arrived and when they left. They can't prove what they did in between but at least they can prove something. I don't think it's a way of saving money-that's my feelingbut I work on the quality assurance side. Obviously it could be used, it can be used for that, but that's where people aren't meeting their business targets and what we expect of them in the contract. But that's not the primary function. The primary function is to make sure that people are

\section{s.moore@greenwich.ac.uk}

\section{The Electronic Monitoring of Care Work—The Redefinition ... 117}

turning up and reassurance that people are going to turn up on time and that something happens if they don't.

The narratives of care workers do not suggest that employers were able to initiate the type of organisational discourses to build trust in technology that Prichard et al. identified as key to mediating the extension of managerial control through technology in healthcare call centres (2014: 821). This may be because of the dispersed nature of the work and limitations on managerial time, however, Prichard et al. also found that workers were able to exercise some discretion in the operation of the technology, lending legitimacy. A care worker suggested her frustration at the lack of trust EM intimated, but also that paid work depended upon use of the technology:

With the clocking in on the phone, I used to forget to do it a lot of the time. I phoned the office to say I've forgotten to log in, she used to say: "Oh, I'll do it for you," but if she didn't I wouldn't have got paid. And I think it's wrong really because they damn well know you're there and damn well know you're at work. Because if you're not there, when you're supposed to be there, that service user would ring the office and say that I hadn't turned up today. [Careworker2] 
The notion of 'big brother' was invoked by a number of respondents, with EM generating a palpable sense of the 'management gaze' and remote signal of control that communicated expectations of compliance (Rosenblat et al. 2014), as one provider reported of the workers she employed across both authorities:

They don't like it and we had a huge resistance when it was first introduced. And, in fact, they introduced the electronic monitoring and what happened was that it affected the quality, the relationship between the carer and the client. It was clock-watching and you hear the "we need to come on, get a move on" sort of thing and "I've got to get to the next person". Well we don't have a choice in it, we won't have any work if we don't comply, the authorities felt that they were paying more, they could pay less. It was financial.

\section{s.moore@greenwich.ac.uk}

\section{S. Moore and L.J.B. Hayes}

Here, the rationale for EM was identified as financial, with concerns raised about its impact on the quality of care shared by a service manager in Local Authority A. He refers to 'the flags' that come up on the computer screen to track the relationship between planned and actual visits and which signal non compliance:

I think it was introduced supposedly for quality purposes although my personal opinion is that it doesn't monitor quality. It's finance-driven actually because before we would pay for what we'd commissioned. So now we pay for the actual, so if they were there for 29 minutes we pay for 29 minutes. For me, the most important thing-what it should do-is be able to monitor the difference- - so the closeness to what we've commissioned to what's actually been provided. We actually don't get a report on the difference between commissioned to provided until the invoice stage which is actually quite late in the process. So we could have commissioned hourly visits but the provider knows that they can't deliver hourly visits so they plan different. And the flags that come up are based on the planned all it does is tells you that somebody turned up, it doesn't tell you what they did. It doesn't talk about the attitude to the way that they provided care, it just tells you that they were in the house for half an hour, they could have been sat there.

Care was seen to be reduced to the correct operation of the telephone system and to watching the clock, as one worker reported:

I found personally — and loads of other people do think this as well- that when you have to clock in and clock out, when you're in a client's house to do the job, you're constantly looking at the time. So you've got half an hour duty to do, you clock in at 10: "Right I've got half hour to get out". And that's what's going through the carer's mind. Because you're not paid if you 
go over your time by five minutes, you're only paid half an hour. If you go over by 10 minutes you're paid, I think you're paid quarter of an hour extra. But then they want to know why it's taken that length of time. Which is fine and understandable I suppose, but I felt like it's big brother watching you. They're rushing all the time. There's no

\section{s.moore@greenwich.ac.uk}

The Electronic Monitoring of Care Work-The Redefinition ... 119

time for human care if you like, not personal care but the human contact care where you can spend time and say; "Are you alright? How you doing?" That's what it's like. [Careworker 6]

As suggested here, care workers perceived that EM constrained the relational aspects of care (Brennan et al. 1999) that are embedded within the commodified care relationship (Ungerson 1999), another care worker confirmed this:

I think if you go in and you've still got your jacket and you're still running around, you're not there with them really. You're just there to feed them and give them a hot drink. I always used to go and take me coat off and put me bag down and ask if they're ok first. And my trouble is I chat too much and, of course, when you're chatting with them and then you make their drink, they don't want you to go. But you know you're looking at that clock and - the chatting, it's companionship, it's definitely part of care. [Careworker2]

Care workers reported returning to clients outside of the EM system to do tasks that they had been unable to finish within paid working time, although others were unwilling or unable to engage in such discretionary labour. Here, the reduction of care to a series of tasks in the Taylorist fashion may undermine the discretionary effort upon which homecare has been dependent since EM makes it absolutely clear that it is unpaid work, as summed up by a provider:

We have had cases where someone has stayed to have a chat - well, the authority aren't going to pay us for you to stay and have a chat with them, that's your time. Log out of your time and then stay and have a chat if you like but you need to go on to your other clients.

This may address Folbre's question as to whether, in the context of a gendered and ethically driven propensity to care, reliance on extrinsic rather than intrinsic motivation might affect the quality of care in the labour market (2012), with contradictory outcomes for women's care labour. 


\section{Conclusions}

Empowerment and disempowerment are defining features of workplace surveillance (Zureik 2003: 66). This account embeds workplace surveillance in the employment relationship, demonstrating that EM goes beyond the recording of working time (Cockburn and Ormerod 1993) and has little potential to empower workers. The case studies of local authorities in the south west of England demonstrate that homecare workers perceive EM as undermining their autonomy and discretion in what is contingent and unpredictable work. They also suggest that it damages the relational aspects of care work. The narratives of the care workers do not suggest that employers have built trust in EM, but articulate their experiences of EM in terms of managerial control and the degradation of their work. They make it clear that they understand EM as a system which sets limitations on their pay, anchoring paid time within service-users' homes.

Unpaid work has become embedded in the organisation of homecare; in combination, ZHC and EM strip so-called 'unproductive' labour from care work. ZHCs provide the contractual basis for episodic work and the non-payment of travel time-here the relationship between paid and unpaid elements of work is unclear because the care worker is seemingly available to the employer when not in the serviceuser's home. Bell and Tuckman assert 'the homogenisation of working time', extending the real subsumption of labour and capital's permeation into free time (2002), with labour increasingly available to capital. The line between time expended in 'labour' (where labour is sold as a commod- ity), and 'free time' outside of that contract (uncommodified outside of exchange) is blurred. In these case studies, EM delineates, rather than blurs, paid and unpaid labour enforcing a spatial and temporal demar- cation between the two whilst simultaneously demanding unbounded availability from the care worker. EM facilitated the payment of providers for client contact only, particularly on a minute-by-minute basis, removing further elements of work from the remit of paid labour. Care workers are penalised if they overrun on calls because of the contingent nature of service user need or if they subsequently run late because of

s.moore@greenwich.ac.uk

The Electronic Monitoring of Care Work-The Redefinition ... 121

such contingencies or because of call-cramming and insufficient travel time. At the same time, they are prevented from leaving before the end of scheduled visits even if not needed which, in the absence of paid travel 
time, is the only way they can claw back paid working time. Whilst hourly rates for homecare workers may be formally at or above the level of statutory minimums (and, in some cases, the Living Wage) an increasing proportion of working time is unpaid bringing paid working time below these minima. In Marxist terms, EM achieves an increase in the rate of relative surplus value through reconfiguring the ratio of unpaid to paid working time and consequently results in an intensifi- cation of work in pursuit of higher productivity (Mavroudeas and Ioannides 2011).

As Zureik maintains the surveillance of work cannot be severed from the surrounding political and economic environment (2003). This study of EM in homecare is located in the political economy of care, where in the context of the retreat of the welfare state, the creation of a market in care and cuts in public spending, local authority commissioning processes place severe competitive pressures on providers to deliver at lower prices. This emphasis on political economy avoids a technologically determinist approach (Howcroft and Taylor 2014) and the reference to case studies of authorities that have adopted UNISON's Ethical Care Charter sug- gests that whilst financial pressures have shaped implementation, there is a commitment to ensuring that care workers get paid a Living Wage and for travel time. Political and financial commitment from council mem- bers (or in the case of Scotland, the government) in response to national and local trade union pressure appear to have made some difference. Here, EM was used more for the purpose of safeguarding and compliance and ethical care was generally considered incompatible with minute-by-minute commissioning. Significantly, however, these case studies showed that the issue of working time and ZHCs is more intractable ${ }^{3}$ in the context of budgetary constraints that remove so-called 'down-time' or define elements of work as apparently 'non-productive'; the 'work-on-demand' model.

The state, in the form of local authorities, engages in third-party surveillance within the homecare employment relationship to benefit from the extraction of unpaid labour from care workers. As Hayes and

\section{s.moore@greenwich.ac.uk}

\section{S. Moore and L.J.B. Hayes}

Moore (2016) have suggested, EM communicates political suspicions that public money may be wasted in paying for care and has to be subject to stringent controls. This challenges the legitimacy of care as a public responsibility and plays into gendered expectations of women's unpaid care labour.

\section{Notes}


1. The Association of Directors of Adult Social Services, described services as at a tipping point where social care was 'in jeopardy' (2016). The Chair of the Local Government Association (LGA), Lord Porter reported that social care faces a funding gap of at least $£ 2.6$ billion by 2020 and that councils would receive nearly one third (31\%) less Revenue Support Grant to run local services in 2017/18 than 2016/17 (LGA, 15/12/16).

2. The National Minimum Wage in 2014.

3. Some authorities have attempted to introduce Guaranteed Hours Contracts to move away from ZHCs, but early evidence suggests these are not fixed-term contracts, but continue to be based upon workers being available to employer demands for variable working time.

\section{References}

ADASS. 2016. ADASS budget survey. ADASS.

Adams, Z., and S. Deakin. 2014. Re-regulating zero hours contracts. Institute of Employment Rights.

Association of Directors of Adult Social Services. 2015. ADASS budget survey 2015 report. ADASS.

Ball, K. 2010. Workplace surveillance: An overview. Labor History 51 (1): 87106.

Bell, E., and A. Tuckman. 2002. Hanging on the telephone: Temporal flexibility and the accessible worker. In Making time: Time and management in modern organization, eds. R. Whipp, B. Adam, and I. Sabelis, 115-125. Oxford: Oxford University Press.

Bessa, I., C. Forde, S. Moore, and M. Stuart. 2013. The national minimum wage, earnings and hours in the domiciliary care sector. London: Low Pay Commission.

s.moore@greenwich.ac.uk

The Electronic Monitoring of Care Work-The Redefinition ... 123

Bolton, S.C., and G. Wibberley. 2014. Domiciliary care: The formal and informal labour process. Sociology 48 (4): 682-697.

Brennan, T., D. Cornell, J. Derrida, and E. Bianchi. 1999. Part 1: Is feminist philosophy, philosophy? In Is feminist philosophy philosophy? ed. E. Bianchi. Northwestern University Press.

Brown, K., and M. Korczynski. 2010. When caring and surveillance technology meet: Organizational commitment and discretionary effort in home care work. Work and Occupations 37 (3): 404-432.

Cockburn, C., and S. Ormerod. 1993. Gender and technology in the making. London: Sage.

Collin-Jacques, C., and C. Smith. 2005. Nursing on the line: Experiences from England and Quebec (Canada). Human Relations 58 (1): 5-32.

Dexter, M., and W. Herbert. 1983. The home help service. London: Tavistock. 
Dominelli, L., and A. Hoogvelt. 1996. Globalization and the technocratization of social work. Critical Social Policy 16: 45-62.

Dooley, L. 2002. Case study research and theory building. Advances in Developing Human Resources 4: 335-354.

Ehrenreich, B. 2001. Nickel and Dimed: On (not) getting by in America. New York: Metropolitan Books.

Folbre, N. 2012. Should women care less? Intrinsic motivation and gender inequality. British Journal of Industrial Relations 50 (4): 597-619.

Glucksmann, M., and D. Lyon. 2006. Configurations of care work: Paid and unpaid elder care in Italy and the Netherlands. Sociological Research Online $11(2)$.

Hayes, L.J.B., and S. Moore. 2016. Care in a time of austerity: The electronic monitoring of homecare workers' time. Gender, Work and Organisation. doi:10.1111/gwao.12164.

Himmelweit, S. 2005. Can we afford (not) to care: Prospects and policy. GeNet Working Paper No, 11. Gender Equality Network, Economic and Social Research Council, Cambridge.

Howcroft, D., and P. Taylor. 2014. 'Plus ca change, plus la meme chose?'Researching and theorising the 'new' new technologies. New Technology, Work and Employment 29 (1): 1-8.

Jacobs, A., and I. Padavic. 2015. Hours, scheduling and flexibility for women in the US low-wage labour force. Gender Work and Organisation 22 (1): 67-86.

Kings Fund. 2016. Social care for older people: Home truths. London: The Kings

Fund.

\section{s.moore@greenwich.ac.uk}

Levy, K. 2015. The contexts of control: Information, power and truck driving work. The Information Society 31 (2): 160-174.

Low Pay Commission. 2013. National minimum wage report, Cm8565.

Mavroudeas, S., and A. Ioannides. 2011. Duration, intensity and productivity of labour and the distinction between absolute and relative surplus-value. Review of Political Economy 23 (3): 421-437.

Prichard, J., J. Turnbull, S. Halford, and C. Pope. 2014. Trusting technology in call centres. Work, Employment \& Society 28 (5): 808-824.

Roper, J., S. Ganesh, and K. Inkson. 2010. Neoliberalism and knowledge interests in boundaryless careers discourse. Work, Employment \& Society 24 (4): 661679.

Rosenblat, A.., T. Kneese, and D. Boyd. 2014. Workplace surveillance. Data and society working paper, Data and Society Research Institute.

Rubery, J., G. Hebson, D. Grimshaw, M. Carroll, S. Smith, M. Marchington, and S. Ugarte. 2011. The recruitment and retention of a care workforce for older people. Department of Health.

Rubery, J., D. Grimshaw, G. Hebson, and S. Ugarte. 2015. It's all about time: Time as contested terrain in the management and experience of domiciliary care work in England. Human Resource Management Journal 54 (5): 753-772.

Skills for Care. 2016. The size and structure of the adult social care sector and workforce in England 2016. Leeds: Skills for Care.

Supiot, A. 2001. Beyond employment: Changes in work and the future of labour law in Europe. Oxford: Oxford University Press. 
Ungerson, C. 1999. Personal assistants and disabled people: An examination of a hybrid form of work and care. Work, Employment E Society 13 (4): 583-600. Ungerson, C., and S. Yeandle. 2007. Cash-for-care in developed welfare states. Basingstoke: Palgrave Macmillan.

UKHCA. 2015. A minimum price for homecare. London: UKHCA.

Zureik, E. 2003. Theorizing surveillance: The case of the workplace. In

Surveillance as social sorting: Privacy, risk $\mathcal{E}$ digital discrimination, ed.

D. Lyon. London: Routledge.

124 S. Moore and L.J.B. Hayes 